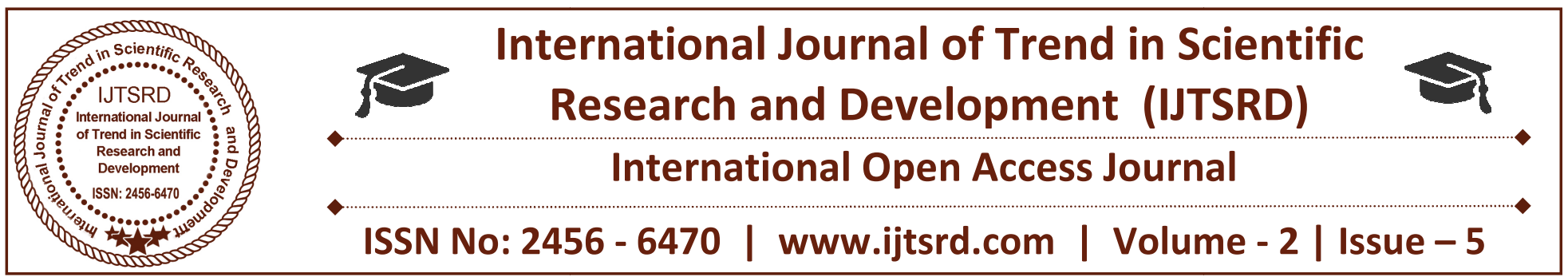

\title{
A Sudy on Consumer Awareness Towards Baba Ramdev and Their Brand "Patanlali"
}

\author{
Neeta Rani \\ Research Scholar \\ IMSAR, Maharshi Dayanand University, Rohtak, Haryana, India
}

\begin{abstract}
Baba Ramdev initiated the "Divya Yog Mandir Trust" in to the year "1995". In the year "2003" a television channel "Aastha TV" started showing their yoga session on their sunrise yoga episode. Here Baba emerged for being television performer as well as received a lot of followers. A numerous range of persons, involving actors and actresses through "India" as well as from foreign, presented within their "Yoga" classes. Baba told about "Yoga" to a lot of actors and actresses such as" Amitabh Bachchan", "Shilpa Shetty"as well as in the abroad nations consisting of "Britain", the "US" and "Japan". Baba too has performed the status of an evaluator within a telegenic episode "Om Shanti Om”. In “2017”, a certain court restricted the deal of Baba's life story, "Journey from God man to Tycoon". In the month of "May 2018", Baba Ramdev initiated "Swadeshi Samriddhi SIM cards" in association through "BSNL".
\end{abstract}

Keyword: Baba Ramdev, Patanjali Ayurved, Consumer awareness.

\section{INTRODUCTION}

"Baba Ramdev" has taken birth through the name of "Ramkishen Yadav" on "25 December 1965". Baba is an "Indian yoga guru" recognized with their effort in Ayurveda and herbal product trade, politics as well as farming. Baba co-initiated the "Patanjali Ayurved Ltd". Baba Ramdev has taken birth in a "Hindu family" his father's name is "Ram Niwas Yadav" as well as mother's name is "Gulabo Devi" at the place of "Hazaribag Ali Saiyad Pur village of Mahendragarh district, Haryana". Their father and mother both were doing farming. Baba told that he

victims as "paralyzed" disease at that time he was two and half year child as well as was after welled through utilizing "Yoga". Baba Ramdev learned "Indian scripture", "Yoga" as well as "Sanskrit" with in diverse schools. Baba has been the learner with their teacher "Acharya Baldevji" into the place of "Gurukul Kalwa". Baba had got "sanyasi diksha" as well as take the identification as "Swami Ramdev" as of "Swami ShankarDev Ji". However residing in "Kalwa Gurukul" with in "Jind district, Haryana", Baba provided without cost "yoga" learning to the village persons. After that Baba reached at "Haridwar "with in "Uttarakhand", there Baba experienced "selfdiscipline" as well as "meditation", also used up numerous days in to the learning of "ancient Indian scriptures" at "Gurukul Kangri Vishwavidyalaya". Baba Ramdev initiated the "Divya Yog Mandir Trust" in to the year "1995". In the year "2003" a television channel "Aastha TV" started showing their yoga session on their sunrise yoga episode. Here Baba emerged for being television performer as well as received a lot of followers. A numerous range of persons, involving actors and actresses through "India" as well as from foreign, presented within their "Yoga" classes. Baba told about "Yoga" to a lot of actors and actresses such as" Amitabh Bachchan", "Shilpa Shetty"as well as in the abroad nations consisting of "Britain", the "US" and "Japan". Baba too has performed the status of an evaluator within a telegenic episode "Om Shanti Om”. In "2017”, a certain court restricted the deal of Baba's life story, "Journey from God man to Tycoon". In the month of "May 2018", Baba Ramdev initiated "Swadeshi Samriddhi SIM cards" in association through "BSNL". 
"Patanjali Ayurved Ltd."

"Patanjali Ayurved" is a fast moving consumer goods corporation, started in "Haridwar", it was originated through the Baba "Ramdev" as well as "Acharya Balkrishna" into the year of "2006". As per the corporation's authorities their turnover into the "March 2016" were "45 billion" along with the monthly turnover of "5 billion". As per the report through "India Info line (IIFL)", not less than "13 listed" corporations would be influenced through the "Patanjali's" achievement involving "Colgate", "Dabur", "ITC" as well as "Godrej Consumer".

\section{REVIEW OF LITERATURE}

1. Chakraborty (2016) in his article, "Babas join queue to ape Patanjali: Sri Sri draws plan to fire up FMCG', analyzed that, For the highest time now, "Baba Ramdev" led "Patanjali" is being seen as the major threat to the listed companies in the "fast moving consumer goods (FMCG)" sector. There are new threats rising, led by the Art of Living pioneer "Sri Sri Ravi Shankar". "After the spectacular initial success of Patanjali, we expect other spiritual gurus (Sri Sri, Guru Ram Rahim, Aurobindo Ashram, and Sadhguru Jaggi Vasudev) also to go the Patanjali way".

2. Vishnoi (2016) in his article, "Ramdev takes ICCR scholars on a tour of Indian culture to Patanjali Yogpeeth" analyzed that, "The Indian Council for Cultural Relations- a government organisation" that's separately operate, chose "Baba Ramdev" and his "Patanjali Yogpeeth" as providing the appropriate type of instruction to foreign scholars interested in learning about the culture and traditions of the country. Foreign scholarship students attended the "Patanjali Yogpeeth" camps in "Haridwar" as well as "Rishikesh" for discussion on spiritual and social issues besides meeting "Ramdev".

3. Vijayraghavan (2016) in his article. "HSBC Global Research cuts target prices of Britannia Dabur and Nestle between 6\% and $16 \%$, says Patanjali" studied that, "HSBC Global Research" has cuts target prices of "Dabur", "Britannia", as well as "Nestle" by between $6 \%$ and $16 \%$, says "Patanjali" an unlisted company troublemaking India's consumer area. A latest research report by the research firm says the growth of "Patanjali" has been nothing short of meteoric, imposing a challenge to the companies that have dominated the consumer place for years. The company, which established as a small pharmacy, has extended to sell the full extent of consumer categories, from edible oils, biscuits, and noodles to toothpaste, hair and skin care products, and groceries.

4. Reddy (2016) in his article, "Baba Ramdev's Patanjali Ayurved ties up with Pluss" concluded that, Pluss, the on-demand medicine and healthcare products supply service has entered into a partnership with "Yoga Guru Baba Ramdev" initiated "Patanjali Ayurved in Delhi". "Patanjali's" categories of "FMCG products", involving staples, groceries, nutrition, hair care, skin care, dental care and toiletries, will be sold by the way of the Pluss App across "Delhi/NCR". Commenting on this tie-up, "Madhulika Pandey, the Co-founder of Pluss" said, "We are quite confident of this tie-up with Patanjali'.

5. Sardar (2016) in his paper, "Desi Hustle Vs MNC Muscle: The Case Study of Patanjali Ayurved Ltd", concluded that, there is no distrust that "Patanjali" is a disruptive force in the "FMCG" area and is a realistic threat for the incumbents, even though "Patanjali" has its challenges. A political agreement with any political party is a double-edged sword as an alteration in political allowance means bad news. For a further, "Patanjali" lacks an army of B-school managers and marketers, at HUL (even though one could disagree that may be a benefit). A sign of that gap was noticeable when, after the start of the atta noodle, "The Food Safety and Standards Authority of India" said that "Patanjali" did not be appropriate for approvals. "Ramdev" reckons all approvals are in place and said that, it may be a plan to destructive him. If he is serious, and it seems he is, it's most probable time for Ramdev to get some management assist in his ranks.

\section{RESEARCH METHODOLOGY}

The research design is descriptive and exploratory in nature, because the aim is to describe about Baba Ramdev and their brand Patanjali herbal marketing and relative important concepts and to find out some implications and suggestions. Primary data was 
collected through personal interview of 100 respondents living in Rohtak district in Haryana district and secondary data was collected through articles, journals, magazines and online sources.

Objective of the study: To study the awareness towards Baba Ramdev and their brand "Patanjali".

FINDING AND CONCLUSION: $88.7 \%$ candidates are aware through "Patanjali" company as well as out of which $65.5 \%$ candidates are utilizing "Patanjali" goods, it indicates higher awareness between the peoples regarding the "Patanjali retail products".

\section{REFERENCES:}

1. Sardar, Ramesh (2016). "Desi Hustle Vs MNC Muscle: The Case Study of Patanjali Ayurved Ltd" Case Studies Journal, School Of Management Studies, North Maharashtra University, Jalgaon, Volume 5, Issue4.

2. Chakraborty, Chiranjivi (2016), "Babas join queue to ape Patanjali: Sri Sri draws plan to fire up FMCG”, ET Bureau.

3. Vishnoi, Anubhuti (2016), "Ramdev takes ICCR scholars on a tour of Indian culture to Patanjali Yogpeeth", ET Bureau.

4. 4.Vijayraghavan, Kala (2016) , "HSBC Global Research cuts target prices of Britannia Dabur and Nestle between 6\% and 16\%, says Patanjali”, ET Bureau.
5. Reddy, Sujata (2016). "Baba Ramdev's Patanjali Ayurved ties up with Pluss" ET Bureau.

6. "Baba Ramdev's Patanjali Group compels FMCG firms Hindustan Unilever and Dabur to expand portfolio". IBT times. 26 January 2016.

7. Yadav, Yatish (9 March 2016). "CISF Team to Guard Ramdev's Food Park". NEW DELHI: Indian Express. http://www.newindianexpress.com/nation/2016/ mar/09/CISF-Team-to-Guard-Ramdevs-FoodPark-901508.html

8. Sharma, Varun (8 March 2016). "Ramdev's Food Park Gets Round-The-Clock Protection From Paramilitary CISF". https://www.ndtv.com/india-news/ramdev-nowa-client-of-paramilitary-force-cisf-for-his-foodpark-1285079

9. "Ramdev's food park gets full-time CISF cover". The Tribune India. 9 March 2016.

10. http://www.india.com/news/india/patanjaliayurved-doubles-its-profit-in-one-year-set-tocatch-up-with-rivals-1051546/

"Patanjali Ayurved doubles its profit in one year; set to catch up with rivals"March22, 2016. 